\title{
A comparative study of obstetrics outcome of placenta previa in scarred versus unscarred uterus at tertiary Hospital, Kathmandu, Nepal
}

\author{
Rakshya Upreti ${ }^{1 *}$, Amit Rauniyar ${ }^{2}$, Sumit Rauniyar $^{3}$, Shaheen N. Ansari ${ }^{1}$, Madan Khadka ${ }^{4}$
}

\begin{abstract}
${ }^{1}$ Department of Obstetrics and Gynecology, Paropakar Maternity and Womens Hospital, Kathmandu, Nepal ${ }^{2}$ Department of Radiodiagnosis and Imaging, National Academy of Medical Sciences, Bir Hospital, Kathmandu, Nepal ${ }^{3}$ Department of General Medicine, King Edward Medical University, Lahore, Pakistan ${ }^{4}$ Department of Obstetrics and Gynecology, BPKIHS, Dharan, Nepal
\end{abstract}

Received: 12 July 2020

Accepted: 20 July 2020

\section{*Correspondence:}

Dr. Rakshya Upreti,

E-mail: rakshyaupreti52@gmail.com

Copyright: ( ) the author(s), publisher and licensee Medip Academy. This is an open-access article distributed under the terms of the Creative Commons Attribution Non-Commercial License, which permits unrestricted non-commercial use, distribution, and reproduction in any medium, provided the original work is properly cited.

\begin{abstract}
Background: Placenta previa is an obstetric life-threatening condition with several maternal and fetal complications. The objective of this study is to compare the maternal and fetal outcome of placenta previa in scarred and unscarred uterus.

Methods: A retrospective case control study was carried out on 85 cases of placenta previa in the department of obstetrics and gynecology, Paropakar Maternity and Womens Hospital (PMWH) Kathmandu from April 2019 to May 2020 of which 46 had scarred uterus and 39 cases had unscarred uterus.

Results: Sixty-one of patients were less than 30 years of age, $62 \%$ presented with gestational age 28 to 37 weeks and $67 \%$ had parity between 1 to 5 . Frequency of placenta previa in scarred uterus was $54 \%$ and that in unscarred uterus was $46 \%$. Eighty percent cases with scarred uterus had anterior placenta compared to $33 \%$ of cases of unscarred uterus with $\mathrm{p}$ value of $0.009 .42 \%$ had grade 4 placenta previa on ultrasonography. 45 percent of patient with scarred uterus had $\mathrm{PPH}$ compared to $23 \%$ in unscarred group with p value of 0.03 . Malpresentation was found in 7 cases in scarred group and in one case in unscarred. Cesarean hysterectomy was performed in 6 cases in scarred category compared to 2 in unscarred. Low birth weight was present in 28 cases in scarred category compared to 15 cases in unscarred category with p value 0.03 .

Conclusions: This study concluded that fetal and maternal outcome is adverse for cases of placenta previa with scarred uterus compared to unscarred uterus.
\end{abstract}

Keywords: Placenta previa, Postpartum hemorrhage, Scarred uterus

\section{INTRODUCTION}

Placenta previa is an obstetric condition in which placenta is implanted partially or wholly in lower uterine segment. ${ }^{1}$ It occurs in $0.3-0.5 \%$ of all pregnancies. ${ }^{2}$ It is an obstetrician's nightmare and a cause for one third of cases of antepartum hemorrhage and around $35 \%$ cases of placental bleeding. ${ }^{3}$

Almost $30 \%$ maternal deaths in the Asian population are due to major obstetrical hemorrhage and placenta previa accounts for a major cause of it. ${ }^{4,5}$ Incidence of antepartum hemorrhage due to placenta previa is rising due to the rise in the incidence of caesarean sections. 6,7 The exact cause of placenta previa is unknown but factors such as abnormal vascularization of endometrium following atrophy, trauma, surgery or infection may reduce the differential growth of lower uterine segment resulting in placenta previa. ${ }^{8}$ Advanced maternal age, multiple gestation, abortions, previous lower segment caesarean section (LSCS), smoking, uterine curettage, previous history of placenta previa are the risk factors for 
placenta previa. ${ }^{9,10}$ Risk of placenta previa with previous LSCS has been found to range between 3 to $10 \% .^{10}$

Placenta previa is an obstetric complication that is potentially life-threatening to both the mother and the baby. ${ }^{11}$ Maternal complication includes antepartum hemorrhage, maternal anaemia, shock, operative interventions like caesarean section and hysterectomy and fetal complications are intrauterine growth restriction, malpresentation, preterm delivery, intrauterine death and stillbirth. ${ }^{12,13}$ Diagnosis of placenta previa can be made by history, examination and investigations as ultrasonography (transabdominal and transvaginal) and magnetic resonance imaging or incidentally during an operation. History may reveal painless bleeding in late second and early third trimester and examination of abdomen reveals soft non tender uterus. ${ }^{14}$ On Leopold's Maneuvers fetal malpresentation may be present in 35 percent cases. Accurate detection of placenta previa helps in proper management and prevention of mortality and morbidity. ${ }^{15,16}$

The objective of the study is to compare the maternal and fetal outcome of placenta previa in scarred and unscarred uterus and to determine the frequency of placenta previa in scarred and unscarred uterus.

\section{METHODS}

This retrospective case control study was conducted at Paropakar Maternity and Women's Hospital (PMWH), Kathmandu, Nepal. Cases of placenta previa from April 2019 to May 2020 were studied.

\section{Inclusion criteria}

- $\quad$ Placenta previa with period of gestation (POG) more than 28 weeks.

\section{Exclusion criteria}

- Pregnancy before 28 weeks

- APH other than Placenta previa

- Multiple pregnancy

- Pregnant women with Hypertension

- Pregnant women with Gestational diabetes or other Comorbid conditions.

A non-probability consecutive sampling technique was adopted for enrolling the patients. All types of placenta previa were included. A total 85 cases meeting the inclusion criteria were enrolled. Booked and unbooked patients both were enrolled. Diagnosis of placenta previa was made by transabdominal and transvaginal ultrasound. Total cases were grouped in two categories.

Group A: 46 cases of placenta previa with history of one or more previous caesarean section or uterine surgery like myomectomy, uterine rupture or uterine curettage.
Group B: 39 cases of placenta previa with no previous history of caesarean section or any uterine surgery like curettage or myomectomy.

\section{Statistical analysis}

All patients who delivered at PMWH over study period with placenta previa were enrolled and categorized into above mentioned two groups. Both the groups of patients were compared with regard to maternal age, parity of mother, fetal outcome and maternal morbidity and mortality. Data was collected using the proforma. Identity of patient and the patient's records were kept confidential. Statistical methods chi-square test and student t-test were used. A p value less than 0.05 was considered significant. Data entry was done using Microsoft excel and analysis was done by using SPSS 16 . Datas are shown in tables and charts below.

\section{RESULTS}

The incidence of placenta previa at Paroparakar Maternity and Women Hospital was $0.3 \%$ over the study period. There were 85 cases of placenta previa out of which 46 cases $(54 \%)$ had scarred uterus and 39 cases $(46 \%)$ had unscarred uterus Table 1.

Table 1: Frequency of placenta previa in two groups.

\begin{tabular}{|lll|}
\hline & $\begin{array}{l}\text { Group A } \\
\text { (scarred) }\end{array}$ & $\begin{array}{l}\text { Group B } \\
\text { (Unscarred) }\end{array}$ \\
\hline Frequency & 46 & 39 \\
\hline Percentage & $54 \%$ & $46 \%$ \\
\hline
\end{tabular}

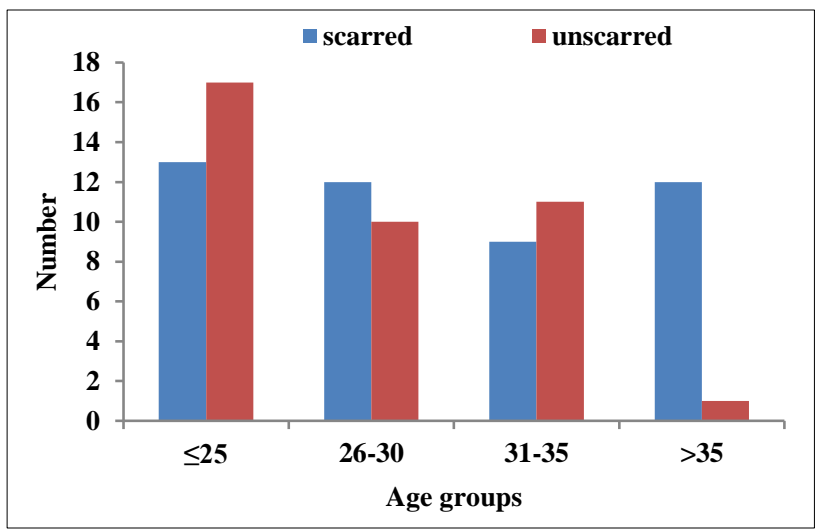

Figure 1: Depicting age groups of patients in scarred and unscarred category.

In this study there were more cases under age group 25 in unscarred category 17 cases $(20 \%)$ compared to 13 cases $(15 \%)$ in scarred category, whereas over the age of 35 more cases were in scarred category $12(14 \%)$ compared to 1 case $(1.1 \%)$ in unscarred category and this was statistically significant with p value of 0.02 Figure 1.

There were 18 cases $(21 \%)$ with parity 0 in unscarred group compared to 9 cases $(10 \%)$ in scarred group which 
was also statistically significant with $\mathrm{p}$ value of 0.02 . Maximum cases of placenta previa were with parity 1 to 5 with total cases of $57(67 \%)$. Gestational age of less than 37 weeks was found in 53 cases $(62 \%)$ of placenta previa Table 2 .

Table 2: Maternal characteristics in scarred and unscarred uterus.

\begin{tabular}{|c|c|c|c|}
\hline $\begin{array}{l}\text { Maternal } \\
\text { characteristics }\end{array}$ & Group A & Group B & $\begin{array}{l}\mathbf{p} \\
\text { value }\end{array}$ \\
\hline \multicolumn{4}{|l|}{ Age group } \\
\hline$\leq 25$ & 13 & 17 & \multirow{4}{*}{0.02} \\
\hline $26-30$ & 12 & 10 & \\
\hline $31-35$ & 9 & 11 & \\
\hline$>35$ & 12 & 1 & \\
\hline \multicolumn{4}{|l|}{ Parity } \\
\hline Para 0 & 9 & 18 & \multirow{3}{*}{0.02} \\
\hline Para 1-5 & 36 & 21 & \\
\hline Para $>5$ & 1 & 0 & \\
\hline \multicolumn{4}{|l|}{ Gestational age } \\
\hline $28-37$ & 29 & 24 & \multirow{2}{*}{0.8} \\
\hline$>37$ & 17 & 15 & \\
\hline
\end{tabular}

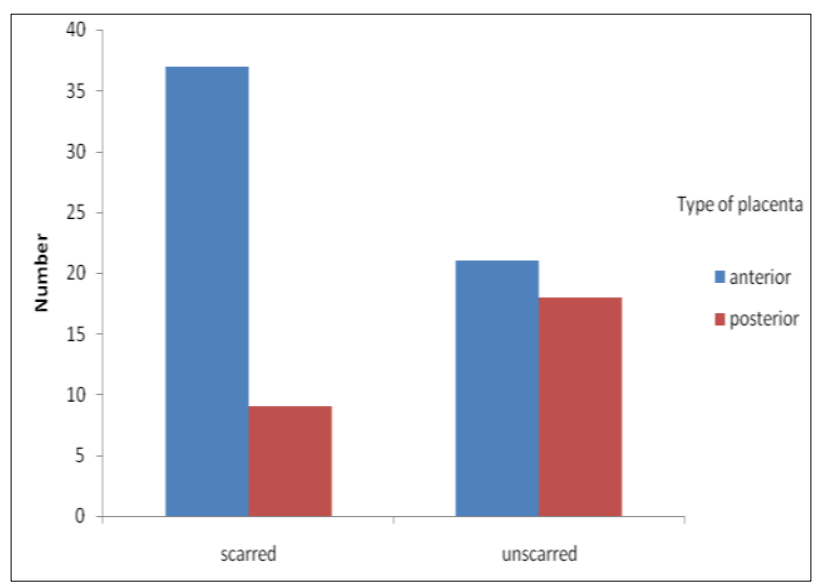

Figure 2: Depicting type of placenta in scarred and unscarred uterus.

Table 3: Type and grading of placenta in scarred and unscarred uterus.

\begin{tabular}{|c|c|c|c|}
\hline & Group A & Group B & p value \\
\hline \multicolumn{4}{|c|}{ Type of placenta previa } \\
\hline Anterior & 37 & 21 & \multirow{2}{*}{0.009} \\
\hline Posterior & 9 & 18 & \\
\hline \multicolumn{4}{|c|}{ Placenta grade } \\
\hline I & 4 & 4 & \multirow{3}{*}{0.4} \\
\hline II & 15 & 14 & \\
\hline III & 9 & 3 & \\
\hline IV & 18 & 18 & \\
\hline
\end{tabular}

A total 37 out of 46 cases ( $80 \%$ with scarred uterus) had anterior placenta which was statistically significant with $\mathrm{p}$ value of 0.009 Figure 2 .
Most of the patient had grade 4 placenta previa on ultrasonography (42\%) Table 3.

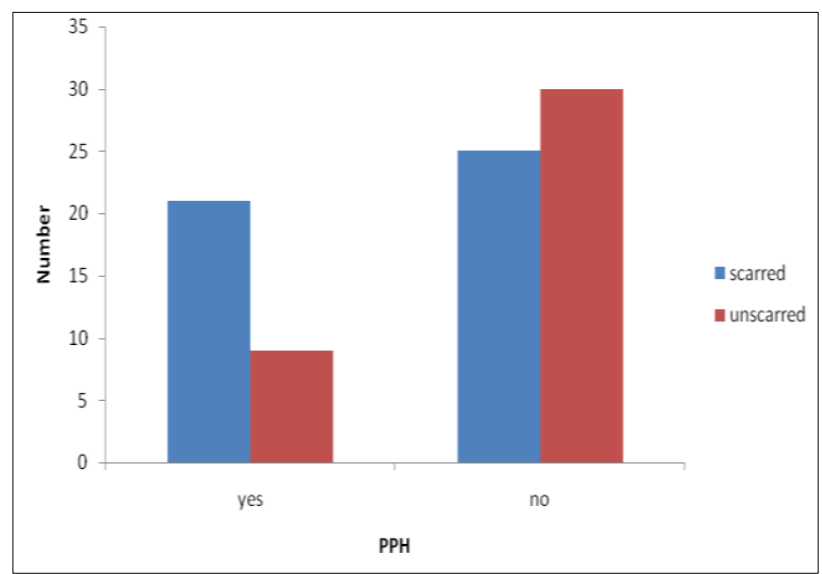

Figure 3: Depicting PPH cases in scarred and unscarred uterus.

Table 4: Related maternal complications in scarred and unscarred uterus.

\begin{tabular}{|llll|}
\hline Complications & Group & Group & $\begin{array}{l}\text { p } \\
\text { value }\end{array}$ \\
\hline PPH & 21 & 9 & 0.03 \\
\hline PPH amount & & & \\
\hline$<1000 \mathrm{ml}$ & 0 & 2 & \\
\hline$>=1000 \mathrm{ml}$ & 21 & 7 & 0.08 \\
\hline Morbidly adherent & 6 & 2 & 0.2 \\
\hline Caesarean hysterectomy & 6 & 2 & 0.2 \\
\hline Malpresentation & 7 & 1 & 0.018 \\
\hline
\end{tabular}

Table 5: Related fetal outcome.

\begin{tabular}{|ll|ll|}
\hline Fetal outcome & $\begin{array}{l}\text { Group } \\
\text { A }\end{array}$ & $\begin{array}{l}\text { Group } \\
\text { B }\end{array}$ & $\begin{array}{l}\text { p } \\
\text { value }\end{array}$ \\
\hline Perinatal mortality & 8 & 7 & 0.9 \\
\hline Preterm birth & 31 & 24 & 0.5 \\
\hline Low birth weight & 28 & 15 & 0.03 \\
\hline
\end{tabular}

Forty five percent of patient with scarred uterus had PPH compared to $23 \%$ of patients with unscarred uterus with $\mathrm{p}$ value of 0.03 which was statistically significant Figure 3.

Average blood loss with cases of PPH in scarred group was $1845 \mathrm{ml}$ compared to $1322 \mathrm{ml}$ in unscarred group. There were 6 cases in scarred category with morbidly adherent placenta compared to 2 cases in unscarred. Malpresentation was found in 7 cases in scarred group compared to 1 case in unscarred with $\mathrm{p}$ value of 0.018 which was statistically significant. Caesarean hysterectomy was performed in 6 cases in scarred category compared to 2 in unscarred Table 4.

Preterm birth was found in 31 cases in scarred category compare to 24 in unscarred Table 5. 
Low birth weight was present in 28 cases in scarred category compared to 15 cases in unscarred with $\mathrm{p}$ value 0.03 which was statistically significant Figure 4.

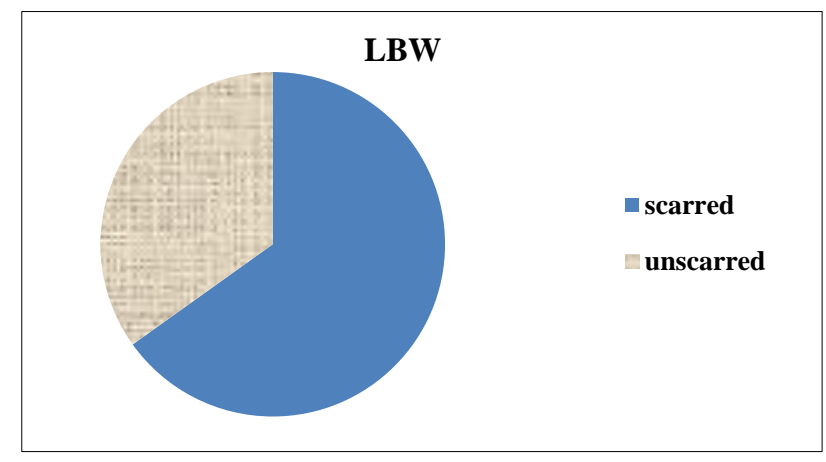

Figure 4: Depicting LBW in scarred and unscarred uterus.

\section{DISCUSSION}

The present study was undertaken to determine the frequency of placenta previa in scarred and unscarred uterus and to compare the fetomaternal outcome. The frequency of placenta previa in scared uterus in this study was $54 \%$ and $46 \%$ in unscarred uterus whereas in the study by Majeed $\mathrm{T}$ et al the frequency of placenta previa in previously scarred uterus was $67.54 \%$ and non-scarred uterus was $32.45 \% .^{17}$

In this study $61 \%$ of cases presented before the age of 30 years compared to $77 \%$ of cases by Faiz et al and $95 \%$ of cases by Rangaswamy et al. ${ }^{2,4}$ Maximum patients were in the age range of 26 to 30 . Placenta previa was present mostly in multiparous with parity 1 to 5 that included $67 \%$ of cases similar to study by Iqbal $\mathrm{K}$ et al which included $48 \%$ of cases. ${ }^{18}$

Two percent cases were delivered by vaginal route compared to other $98 \%$ cases by caesarean section. This finding was consistent to study by Rnagaswamy et al. ${ }^{4}$

In the study by Nair D et al postpartum hemorrhage was present in $69 \%$ in scarred uterus compared to $48 \%$ cases in unscarred whereas in this study it occurred in $45 \%$ of patient with scarred uterus and $23 \%$ with unscarred uterus which was statistically significant. ${ }^{19}$

Anterior placenta previa was present in $80 \%$ of cases with scarred uterus compared to $62 \%$ cases of scarred uterus by Khansa Iqbal et al and $66 \%$ of cases by RD Katke. ${ }^{15,20}$ Complete placenta previa was present in $42 \%$ of total cases compared to $20 \%$ by Rangaswamy et al and $22.7 \%$ by Vaishali et al. ${ }^{4,21}$

In this study 8 cases had morbidly adherent placenta, 6 cases in scarred and 2 cases in unscarred, these findings were parallel to study by Mansi et al where 6 cases had invasive placenta and $3 \%$ of cases in scarred uterus had placenta accreta while $2.9 \%$ in unscarred uterus had placenta accreta. ${ }^{22}$ This value in this study was not statistically significant probably due to smaller sample size.

There was no maternal mortality during the period. However, 9\% case i.e., 6 patients with scarred uterus and 2 cases with unscarred uterus have torrential PPH leading to peripartum hysterectomy, ICU stay and prolonged morbidity. This result was also consistent to the study by Syeda et al where hysterectomy was performed in $12 \%$ cases. $^{7}$

Malpresentation was found in 7 cases in scarred group compared to 1 case in unscarred with $\mathrm{p}$ value of 0.018 which was statistically significant. This association may be explained by anterior placentation obstructing the engagement of head in scarred uterus. Perinatal mortality did not differ between two groups. However, LBW was present in $60 \%$ of cases with scarred uterus compared to $38 \%$ cases with unscarred uterus. It could be explained by placental bleeding leading to hypoxia and intrauterine growth retardation. ${ }^{14}$

\section{CONCLUSION}

Scarred uterus caused by uterine intervention such as LSCS and MVA are associated with adverse fetomaternal outcome. Reduction in the rate of these procedures along with regular ANC visits, early diagnosis by USG and early planning of deliveries will reduce the complications associated with placenta previa.

Funding: No funding sources Conflict of interest: None declared

Ethical approval: The study was approved by the Institutional Ethics Committee

\section{REFERENCES}

1. Arulkumaran SS. Best practice in labour and delivery. 1st ed. Cambridge, United Kingdom; NewYork: Cambridge University Press; 2009: 141145.

2. Faiz AS, Ananth CV. Etiology and risk factors for placenta previa: an overview and meta-analysis of observational studies. J Matern-Fetal Neonatal Med Off J Eur Assoc Perinat Med Fed Asia Ocean Perinat Soc Int Soc Perinat Obstet. 2003(3):175-90.

3. Kanak L, Gita BB. Fetomaternal outcome in placenta preiva with and without previous cesarean section-a prospective study. J Dent Med Sci. 2017;16(7):30-5.

4. Rangaswamy M, Govindaraju K. Fetomaternal outcome in placenta previa - a retrospective study in teaching hospital. Int J Reprod Contracept Obstet Gynecol. 2017;5(9):3081-4.

5. Parvin Z, Das S, Naher L, Sarkar SK, Fatema K. Relation of placenta praevia with previous lower segment caesarean section (LUCS) in our clinical practice. Faridpur Med College J. 2017;12(2):75-7. 
6. Ahmed SR, Aitallah A, Abdelghafar HM, Alsammani MA. Major placenta previa: rate, maternal and neonatal outcomes experience at a tertiary maternity hospital, Sohag, Egypt: a prospective study. J Clin Diagn Res. 2015;9(11):QC17-19.

7. Uzma S, Kiani BA, Khan FS. Frequency of placenta praevia with previous cesarean section. Ann Pak Inst Med Sci. 2015;11(4):202-5.

8. Dashe JS, McIntire DD, Ramus RM, Santos-Ramos R, Twickler DM. Persistence of placenta previa according to gestational age at ultrasound detection. Obstet Gynecol. 2002;99(5 Pt 1):692-7.

9. Mohamedsalih DY, Hameed NR, Faisal S. Effect of previous scar uterus and sit of placentation on early pregnancy on early pregnancy outcome in Iraq. Int $\mathbf{J}$ Adv Res Biol Sci. 2018;5(5):100-25.

10. Bashir A, Jadoon HN, Abbasi AU. Frequency of placenta previa in women with history of previous caesarean and normal vaginal deliveries. J Ayub Med Coll Abbottabad JAMC. 2012;24(3-4):151-3.

11. Lama $S$, Ranjit S. Study on maternal and immediate fetal outcome of placenta previa. Nepal J Obstet Gynaecol. 2016;22(2):24-7.

12. Kavitha B, Hota BM. Clinical study of placenta previa in scarred and unscarred uterus. J Dr. NTR University Health Sci. 2018;7(1):13.

13. UM, SR, SS. Placenta previa with history of previous caesarean delivery - an obstetrician's nightmare. J Womans Reprod Health. 2017;1(4):33.

14. Senkoro EE, Mwanamsangu AH, Chuwa FS, Msuya SE, Mnali OP, Brown BG, et al. Frequency, risk factors, and adverse fetomaternal outcomes of placenta previa in Northern Tanzania. J Preg. Hindawi. 2017:e5936309.

15. Tahseen H, Tahira T, Hafiz S, Noreen Z. Placenta previa: a comparative study of obstetrics outcome in previously scarred and unscarred uterus at services hospital, Lahore. Pak J Med Health Sci. 2018;12(3):889-91.

16. Yadava P, Patel R, Mehta A. Placenta previa: risk factors, feto-maternal outcome and complications. Int J Reprod Contracept Obstet Gynecol. 2019;8:4842.

17. Majeed T, Waheed F, Mahmood Z, Saba K, Mahmood H, Bukhari MH. Frequency of placenta previa in previously scarred and non-scarred uterus. Pak J Med Sci. 2015;31(2):360-3.

18. Iqbal K, Abid R, Irfan R, Shaheen F. Comparison of fetomaternal outcome between scarred and unscarred uterus in placenta parevia cases. J Soc Obstet Gynaecol Pak. 2016;6(3):102-6.

19. Nair DB, Murukesan L, Menon S. The effect of previous obstetric interventions in the outcome of placenta previa. Int $\mathbf{J}$ Reprod Contracept Obstet Gynecol. 2017;6(11):4879-85.

20. Katke RD. Placenta previa: outcomes in scarred and unscarred uterus. Int $\mathbf{J}$ Reprod Contracept Obstet Gynecol. 2017;5(8):2728-32.

21. Shinde DV, Rachkonda DL. A study on maternal and neonatal outcomes in placenta previa in a tertiary level hospital in India. Int J Med Sci Clin Invent. 2015;2(12):1480-4.

22. Shrigiriwar M, Kesarwani S, Ramteke S. Fetomaternal outcome in placenta previa in scarred versus non-scarred uterus. Int $J$ Sci Study. 2019;6(11):13-8.

Cite this article as: Upreti R, Rauniyar A, Rauniyar S, Ansari SN, Khadka M. A comparative study of obstetrics outcome of placenta previa in scarred versus unscarred uterus at tertiary Hospital, Kathmandu, Nepal. Int J Reprod Contracept Obstet Gynecol 2020;9:3183-7. 